\title{
E(RA)N TIEMPOS DE DESCONCIERTO: DELACROIX Y SU CANTO A LA LIBERTAD
}

\author{
Manuel Núñez Rodríguez \\ Universidade de Santiago de Compostela
}

\section{RESUMEN}

Sabido es que el 27 de julio de 1830 los parisinos forman barricadas bajo una proclama popular que consiste en cambiar a un rey tirano (el Borbón Carlos X), por uno más liberal. Esto supone el éxito de la revuelta, de manera que el 2 de agosto del mismo año alcanzará el poder Felipe de Orleáns bajo la condición de rey del pueblo. Aunque se abordará esta cuestión en líneas sucesivas, de momento interesa conferir un puesto de privilegio al documento que da vida a lo que fue un estado de excitación febril, pero que -como diría Eugène Delacroix- en síntesis no es más que la historia de una idea. De manera que se trata de acceder al análisis del contenido que esta obra ofrece y hasta qué punto estamos en condiciones de evaluar el significado de la expresión icónica; es decir, de acceder críticamente al contenido del mensaje de este cuadro (La libertad conduciendo al pueblo, 1830-1831), asociada a los ideales de la revolución de 1789, a la que tuvo que rendir homenaje el nuevo "rey ciudadano" Luis-Felipe de Orleáns cuando resucitó en 1831 el uso de la bandera tricolor como símbolo de Francia.

Palabras clave: libertad, república, Delacroix, tradición clásica, espíritu de la revolución

\section{ABSTRACT}

On 27 July 1830 the Parisians built barricades in support of a popular proclamation that sought to depose a despot king (the Bourbon Charles X) for a more liberal one. The revolt proved to be successful, with Louis Philippe I coming to power on 2 August, on condition that he ruled in the interests of the people. Although this issue will be addressed below, our interest at this stage lies in granting a prominent position to the document that gave rise to what was a state of some excitement but which -as Eugène Delacroix said-is, in summary, merely the history of an idea. This aim of this paper, therefore, is both to analyse the content provided in this work and the extent to which we are in a position to evaluate the meaning of the iconic statement, in other words, to critically approach the message of the painting (Liberty Leading the People, 1830-31), which was associated with the ideals of the 1789 Revolution and to which the new "Citizen King", Louis Philippe I, paid tribute in reviving the use of the Tricolour as a symbol of France in 1831.

Keywords: liberty, republic, Delacroix, classical tradition, the spirit of the revolution

El tema es algo distinto de la noción; esto presupone hacer empleo de los componentes básicos para trasladar a la idea plástica lo que una imaginación creadora selecciona.

Eugène Delacroix
Es verdad que Frédéric-A. Bartholdi, con su estatua de la Libertad, sujetando con la diestra la antorcha que ilumina al mundo, ponía de manifiesto un concepto asociado a los que entraban en Nueva York desde 1884-1886, donde eran examinados antes del ingreso en el país. Se consideraba entonces esta imagen de 10 metros de altura la expresión icónica de la democracia (in- 


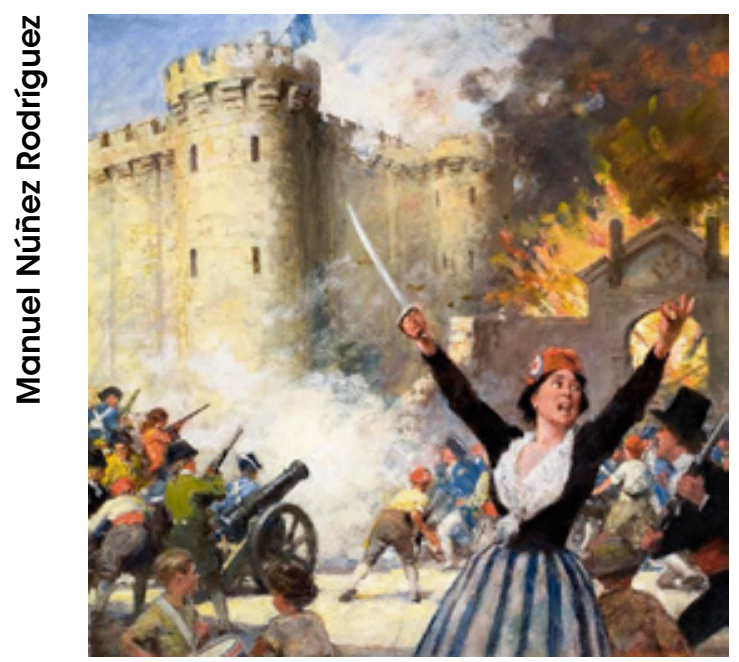

Fig. 1. Théroigne de Méricourt o "la amazona de la Libertad". Toma de la Bastilla en 1789, Escuela Inglesa (Fuente: Getty Images)

terpretación que hoy no podríamos experimentar ante las confusiones que podría provocar, puesto que se diría que es un ideal inalcanzable en las actuales circunstancias). Ahora bien, hay una cuestión que no deja de ser curiosa, y que incluso parece inexplicable en el mundo francés. Se trata del siguiente comportamiento, al que, como se verá, rodea un halo de misterio envolvente inexplicable: cuando China solicitó en préstamo La Libertad guiando al pueblo (el 11 de diciembre de 2013), Laurent Fabius, ministro de Asuntos Exteriores, apoyado por la célula diplomática del Elíseo, estaba deseoso de que dicha obra formara parte del conjunto de obras prestadas por Francia a China con motivo del $50^{\circ}$ aniversario del reconocimiento de la República Popular China por el general De Gaulle el 27 de enero de 1964. A mayores hay que considerar que, aunque diferente, existe en la plaza de Tien-an-Men (Pekín) la estatua china de la diosa de la Democracia de 1989 en honor de los estudiantes de la Escuela Central de Bellas Artes, y que constituye un testimonio revelador de los manifestantes. Pero, dadas las consecuencias por todos conocidas en tiempos de Mao Zedong, podría ser la razón sobre la negativa del préstamo al no mostrarse los franceses acordes, identificados con la tradición, en concreto con la creación del mensaje combativo que Delacroix buscó transmitir en esta obra acorde con las circunstancias del momento, y que analizaremos en líneas sucesivas: la Guerra de los tres Días (27, 28 y 29 de julio de 1830).

En cualquier caso, el ministro de cultura no concuerda con la posición del presidente del Louvre, Jean-Luc Martinez, quien se opone al desplazamiento de la obra, proponiendo a cambio el retrato de Francisco / y Le verrou de Fragonard. La única preocupación era el próximo desplazamiento a Francia del presidente chino Xi Jinping en la primavera de 2014.

Para abordar la figura de este pintor, cuyo recuerdo no ha quedado anclado en el pasado, hay que plantear ante todo un interrogante: ¿predomina en su obra la imaginación o la memoria? Cierto es que si se hace un balance de su labor, hay una presencia de Rubens, Miguel Ángel, Rafael, Veronés, así como de una figura como Murillo, entre otros varios -como podría ser el caso de Rembrandt-, puesto que son personajes que forman parte del Museo del Louvre. Un centro en el que, salvo excepción, se han formado la mayor parte de los artistas de la época moderna, y sobre todo Delacroix, si tenemos en cuenta que a él le sería encomendado por Thiers la guardia de dicho museo durante la Guerra de los Tres Días (27, 28, 29 de julio, 1830); denominada también "Ios tres días de insurrección". Un momento en el que la llamada Venus de Milo accedía a dicho museo.

En realidad, recordar este dato es anticiparse a algo que alimentará nuestro objetivo páginas adelante, cuando habrá que dar respuesta al contenido de la carta que Delacroix había escrito a su hermano el 17 de agosto de 1830:

Hemos estado durante tres días en medio de la metralla y tiros de fusil, pues se combatía por todas partes. Un simple paseante como yo tenía la posibilidad de ser alcanzado por una bala, como el héroe improvisado que camina hacia el enemigo con trozos de hierro en mangos de escoba. Hasta aquí todo muy bien.

El texto no deja de ser importante, puesto que como veremos nos interesa para saber si el pintor no solamente estaba a favor de la corriente republicana, sino también si, a pesar de no haber formado parte de las figuras combatientes en las barricadas, lo que busca representar es el símbolo de la nación, el culto a la Patria; como también incrementar la conciencia política de quienes no 
aceptan los criterios que proceden de la Revolución Francesa, comenzando por la igualdad. Ahora bien, siempre sin dejar de considerar que sin la libertad "todos somos iguales bajo un tirano" y la antimonarquía era la república.

Pero resulta de mucha importancia detenerse y analizar más de cerca la variable interpretativa, los elementos que pudieron haber influido en la recepción del mensaje semántico de la Libertad. Dicho de otra manera, el contenido de esta expresión icónica ha llevado a múltiples preguntas de orden teórico de las que solamente se puede hacer una selección, para resumir, y evaluar otros conocimientos que nos parecen de mayor importancia. En principio Charles Baudelaire, lo mismo que Delacroix, muestra un desprecio por la mujer, aunque ella sea su capítulo a investigar, pero no su amor ${ }^{1}$. Por otra parte, al considerar que esta es una época de puritanismo, y Delacroix partidario de la libre expresión, demuestra un perfecto conocimiento del desnudo desde sus inicios (Estudio del hombre desnudo o El polaco, Museo Eugène Delacroix, París). Pero en el caso de la mujer, ¿pudo haber llegado lejos de no haber aplicado la mirada oblicua, como era su referencia dominante? E incluso, ¿hasta qué punto en un ejemplo de narrativa bélica como es La Libertad guiando al pueblo (fig. 2), donde se plantea un episodio victorioso, Delacroix no intenta una manera de hacer distinguir la trascendencia que tuvo la mujer en la Primera República francesa, en lo que fue su emblema, que consiste en la representación de la Libertad con una bandera? Por principio hay dos cuestiones que serán abordadas en líneas sucesivas: la primera es la importancia que pudo haber tenido la iconografía de la figura alegórica de la Primera República atribuida a J. A. Gros; y la segunda cuestión a evaluar en líneas sucesivas es el significado de la expresión icónica de las imágenes que han sido utilizadas en las litografías vinculadas a la toma de la Bastilla, y donde se reconstruía la experiencia de las mujeres a pecho descubierto (fig. 1), tocadas con gorro frigio, y portando mosquete en la liberación de la cárcel parisina, conforme a los ideales de la revolución de 1789 .

Pero igualmente, entre otros factores, lo que cabe preguntarse es si en verdad Delacroix no estaba demostrando una cierta admiración por

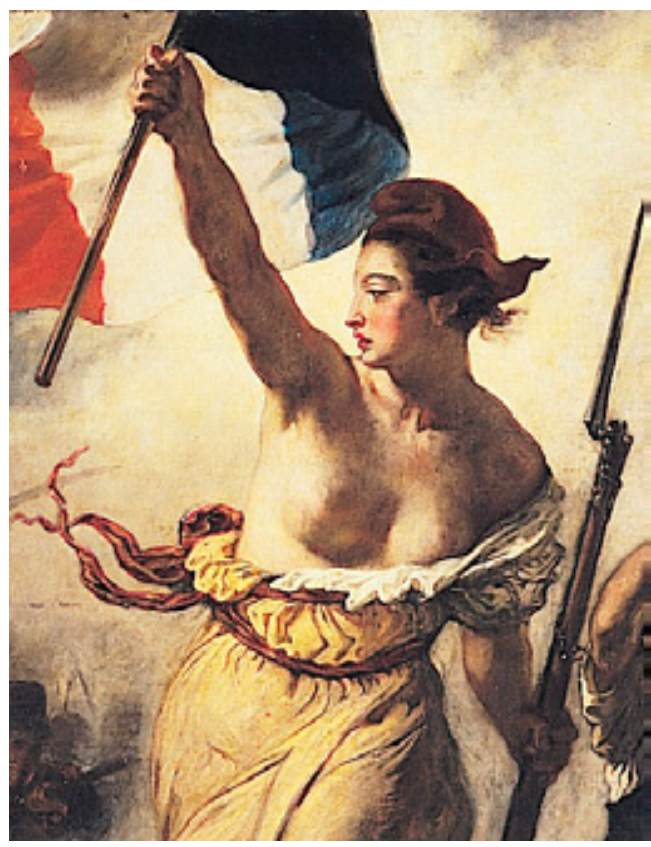

Fig. 2. Detalle de la Libertad. La Libertad guiando al pueblo, de Eugène Delacroix. 1831. Paris, Musée du Louvre

la figura de la Venus de Milo, puesto que, como veremos en su momento, si hay un dato al que no se le ha dado una interpretación satisfactoria es el correspondiente a la valoración correcta de los pechos al descubierto de la Libertad. Por esta razón habrá que tener en cuenta en primer lugar que Delacroix tenía un especial interés por el mundo clásico, por el desnudo de la mujer griega, puesto que en sus palabras demostraba estar en posesión de un gran conocimiento del dibujo, al igual que de la poesía. Por otra parte este era un momento de vuelta a la representación de las divinidades griegas, tanto en pintura como en escultura, y nada impide inspirarse en su espíritu, ya que es la expresión de lo natural y al mismo tiempo de lo elevado.

Entonces, si retomamos la diferencia planteada al principio -memoria/imaginación-, Delacroix marca desde un primer momento cuál es la consideración que se impone en estas dos facultades opuestas: la memoria es la que permite almacenar recuerdos; como se diría hoy, es el disco duro donde guardamos imágenes, sentimientos, recuerdos. La diferencia con los ordenadores es que estos mineralizan, mientras que la memoria 
recrea un recuerdo que nosotros nos contentamos con descodificar.

El hecho es que en el proceso de la obra, Delacroix podrá utilizar la memoria a partir de aquellos textos que ha leído, de aquellas pinturas que ha visto y que le han marcado. $Y$ en este sentido especialmente hay dos, Rubens y Veronés, a los que admira por el color, y así Delacroix llegará un momento en que es tal la admiración que demuestra por el flamenco que le dirá: "Gloria a este Homero de la pintura, a este padre del color y del entusiasmo, en este arte donde lo supera todo, en virtud de la perfección que ha conferido a tal o cual parte, pero también a esa fuerza secreta y esa vida del alma que ha infundido por doquier". Admiración que también le lleva a demostrar lo propio por Rembrandt, quien, como él decía, "ha sabido otorgar hondura expresiva a las figuras vulgares, es un pintor mucho más grande que Rafael" (lo que no quiere decir que Rafael y su obra representen un referente por el que no muestre la correspondiente fidelidad).

Por otra parte están los vericuetos de la imaginación. Al hacer un análisis de la obra que está en el Louvre, curiosamente tanto los guías como las monografías muestran una especial predilección por aquellas obras que han formado parte de la etapa de su vida marcada por sus vínculos con Víctor Hugo y con el Arsenal de Charles Nodier, correspondiéndose con los años de Carlos X. Las obras son La masacre de Quíos (1824), una pintura que tiene como referente la lucha de la independencia de los griegos contra la dominación otomana; La muerte de Sardanápalo (1827), obra donde se aprecia una fuerte influencia de Lord Byron y Rubens; y luego, finalmente, La libertad guiando al pueblo o Los tres días de las trágicas jornadas revolucionarias (1830), presentada en el "Salón" en 1831.

Esta última es una obra donde tenemos además el recuerdo de Théroigne de Méricourt, heroína de la Revolución Francesa denominada la "Amazona de la Libertad" (fig. 1), quien participara en los actos del 10 de agosto de 1792 cuando el palacio real fue asaltado por el pueblo (a este personaje habrá que referirse más adelante). La razón está en que el proceso de creación de este cuadro parece seguir exactamente esos pasos; es decir, Delacroix no queda anclado en los recuerdos, sí en la realidad, puesto que en este momento, aunque retorna la monarquía con Luis Felipe de Orleáns, es mediante un pacto entre la nación y el rey, para indicar que son los franceses quienes otorgan la soberanía. Lo cual implica la vuelta a la bandera tricolor -que fuera prohibida desde los tiempos de Napoleón-, así como al himno revolucionario (La Marsellesa), si bien este, compuesto en 1792, será en la tercera República cuando volverá a ser adoptado para la fiesta nacional del 14 de julio.

Entonces, para concluir este apartado, la imaginación supone reconstruir un pasado que fue ficción durante la época de los Borbones, y que ahora cobra interés con este cuadro de La libertad guiando al pueblo, donde se propone como argumento a esgrimir, por una parte, la defensa de la república (capítulo que no pudo llevarse adelante por los impedimentos de los británicos hasta Metternich); pero sin embargo cobra forma la exaltación del patriotismo, y con él se ponía en marcha la importancia de la libertad, la paz y la justicia, con un gobierno de Luis Felipe de Orleáns (1830-1848) a la inglesa.

Ahora interesa saber el criterio de Baudelaire sobre Théroigne de Méricourt. Para ello se impone acudir al poema LIX de Las Flores del Mal, que lleva por título "Sisina"2:

(...) ¿Habéis visto a Théroigne, la que ama las masacres excitando al asalto al pueblo sin zapatos, mejillas y ojos íneos, haciendo su papel, subiendo, sable en mano, los peldaños reales?

La imagen que aquí se cita es la también llamada, cuando regresa a París el 26 de enero de 1792 y es recibida con todos los honores por los jacobinos, "Primera amazona de la Libertad" (fig. 1). Al observar estas dos ilustraciones, en la primera aparece Théroigne o "la amazona de la Libertad", quien participa activamente en los acontecimientos del 10 de agosto de 1792 durante el asalto del Palacio real por el pueblo, después de haber formado parte de la vanguardia en la toma de la Bastilla el 14 de julio de 1789, donde se presentó empuñando una espada -arma que manejaba como si fuera una pistola- juntamente con un grupo de mujeres dispuestas al combate. Alfonso de Lamartine decía que "era una mujer joven y hermosa, vestida de hombre, con un fusil y sentada sobre un cañón que arrastraban 
los jornaleros"; pero sobre todo insistía en que llevaba los brazos desnudos, y en el jardín de las Tullerías las mujeres jacobinas la creen una traidora de la revolución y le desgarran la ropa. Según parece las militantes jacobinas daban como castigo la flagelación. Es importante considerar en este apartado el cartel elaborado por los nostálgicos del Antiguo Régimen (fig. 3), realizado en el año 1880, denunciando la celebración de la fiesta nacional del 14 de julio y los crímenes de la Revolución; en él aparece la imagen de la República coronada de serpientes, vestida con cabezas de muertos, entre el incendio y la guillotina, y a los pies los símbolos de lo que representó la Revolución; es decir, la separación de los dos poderes. Por otra parte, la heroína en el pasado, pasa a convertirse en cortesana enfurecida, inquieta y vacía, transformándose radicalmente los privilegios del sexo femenino por la identidad declarada de la mujer déspota. ¿Se puede decir que ahora estamos ante la amazona que grita para para confirmar la Libertad de Francia? En absoluto.

En cuanto a la Libertad, será analizada en líneas sucesivas, pero sirva como anticipo que si algo no parece admisible es que en la actualidad se muestre dicho tema portando una guitarra eléctrica y en una actitud pudibunda. Ya no se diga en los pueblos del Golfo, donde tal tema está prohibido en los manuales escolares turcos, e incluso resulta célebre un timbre ruso en donde la demanda de hipocresía sexual impone su presentación completamente vestida de negro.

\section{El arsenal de Charles Nodier (1824-1834)}

Los estudios realizados sobre Delacroix han sido múltiples, en consecuencia el planteamiento de este trabajo no puede incidir en conceptos elaborados sobre su obra. Por el contrario, interesa considerar preferentemente cuestiones que guardan relación con sus ideas y aspiraciones, con las necesidades y esperanzas de una situación histórica particular que habría de derivar en un principio de revuelta social, o mejor, de perturbación violenta.

Los testimonios que existen sobre aquella realidad son cada vez más numerosos, y permiten llegar a la conclusión de que la estética de la creación artística de este poliédrico autor de un

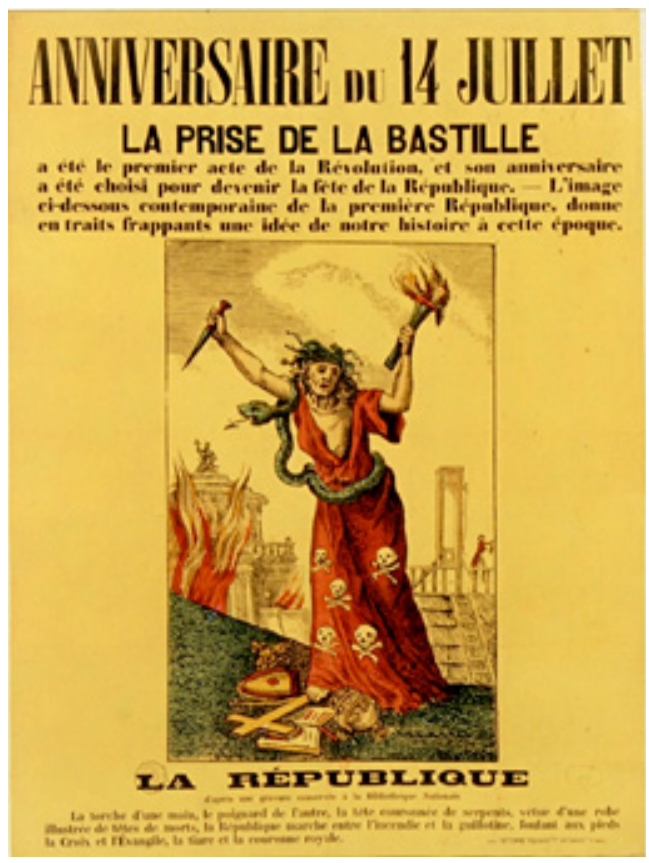

Fig. 3. Anniversaire du 14 Juillet. La prise de la Bastille, Cartel del aniversario de la Toma de la Bastilla el 14 de julio (1880), según los que rechazaban la Revolución (Colección A. Gesgon/ CIRIP et Roger-Viollet)

estilo propio representa, no solo un esfuerzo personal consecuencia de una auténtica imaginación creadora, sino también resultado de una novedad técnica en consonancia con su propio modo o práctica, capítulo consustancial con quien está caracterizado por una originalidad y un esfuerzo para eludir las denominadas teorías academicistas de los géneros artísticos. Pero previamente a la expresión de la medida de su grandeza, al artista y su capacidad para poner de relieve los rasgos esenciales que hacen referencia a su base creativa (simbiosis-romanticismo-subjetividad), hay dos capítulos a considerar cuando la unidad aparente se desintegra y la lucha de clases vuelve a estallar en un país con el triunfo de la derecha liberal que terminará por ser sustituida en la célebre revolución de julio del 1830. Pero esta llamada de trompeta ocurrirá en 1824 con la derecha ultracismática opuesta a la carta de 1814, con Carlos $X$ de Borbón. Su nueva propuesta supondrá en 1827 la hegemonía de una verdadera contrarevolución, puesto que se consideraba que "la Revolución francesa" -según el vizconde Louis de Bonald- había sido un Ilamamiento a todas 
las pasiones, violencias y errores, de modo que definía el concepto del mal elevado a su máxima potencia ${ }^{3}$.

Entonces, ¿cuál puede ser considerado el paso siguiente? Según parece, en líneas generales, unos argumentos suelen centrarse en la anulación de lo que fueron las leyes impías de la Revolución. ¿Y esto, qué significaba?, el retorno a la alianza trono-altar, con misiones católicas para reconvertir al pueblo y, todavía en 1825, se preveía la pena de muerte en la ley contra actos de sacrilegio. Todavía más, para no alargar la lista cuando en 1828 Delacroix presenta en el salón en 1827 La muerte de Sardanápalo (fig. 4), varios juicios llevaron a la crítica a confundir maldad y violencia con lo que Simone de Beauvoir ${ }^{4}$, así como Edward Lucie-Smith o Linda Nochlin ${ }^{5}$, entre otros no dudan en definir como libre expresión de las pasiones individuales bajo los efectos de los escritos del marqués de Sade, donde el romanticismo juega además con la experiencia junto con la memoria, las disposiciones de Sardanápalo, la imaginación..., para defenderse con tales herramientas, del miedo que produce el presente y el futuro que toca crear. Movimiento opuesto al de un neo-clasicista, más acorde con el orden de la lógica, incluso cuando se trata de confrontar el planteamiento del nudismo en Ingres y en Delacroix, en el primero no deja de detectarse "un cierto puritanismo"; por el contrario el segundo, "la experiencia la transforma en emoción", demostrando en este cuadro sus dotes para el desnudo o, por lo menos, la importancia concedida a la expresión de las pasiones y sentimientos ${ }^{6}$.

Sin adentrarnos en las protestas de la "liga moral", quienes prolongaron el romanticismo de Delacroix y son definidos como simbolistas, así Gustave Moreau (1826-1896) aunque frecuenta a Delacroix y su obra no es que llegue a imitarlo7, pero lo acoge de igual manera que admira a Miguel Ángel, siempre sin imitarlos. Y aquí vienen las diferencias. Sus personajes parecen invocar el recuerdo que anida en la cárcel oscura de su mente ya que hace acto de presencia un atractivo por el "metamorfoseado" de manera que transforma la energía de los hombres, como también de las mujeres, en personajes que no pocas veces resultan equívocos. Tal es la propuesta de su obra denominada Messalina (sin data, Museo Moreau,
Paris), o Salomé, donde se trata de determinar la inmadurez, la depravación y la condición de mujer frígida. De manera que conforme al planteamiento de Edw. Lucie-Smith la satisfacción que ella busca con tanto ardor "gravita fuera de su alcance", en el mismo instante en que condena el instrumento de su posible gozo. Existe por consiguiente una mirada oblicua con respecto a la mujer.

Simone de Beauvoir, cuando escribe, demuestra que las palabras no son inocentes, y cuando el travestismo se afinca en el lenguaje, siempre hay una víctima. En su estudio sobre el Marqués de Sade, nos habla del hombre imperioso, colérico, impulsivo, exagerado en todo, con un desorden en la imaginación, en lo que atañe a las costumbres, ateo hasta el fanatismo, y algo más: "matadme o aceptadme tal cual soy, pues no cambiaré" 8 . Se diría que en estas palabras se reconoce de buena gana a un Delacroix que fue un gran bocetista, y que un día en un encuentro con un colega le comentó que la gran preocupación de toda su vida era "ejecutar con bastante rapidez y certeza, para que no se evaporara la idea, de manera que la imaginación creadora pudiera sumergirse en lo fundamental, y distanciarse de

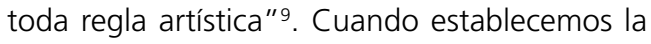
lectura de la Muerte de Sardanápalo (fig. 4), el autor reenvía a las masacres perpetradas por los otomanos durante la guerra de la independencia griega, aunque el cuadro se inspira en el drama Sardanápoulus de Lord Byron.

Si la Muerte de Sardanápalo todavía hoy es capaz de sorprender en lo que atañe a la mujer por la evidente crueldad, es porque su autor adopta una actitud en la que experimenta placer haciéndola sufrir mediante la conmoción más violenta posible. De manera que el dolor o es equivalente al placer o, por el contrario, la violencia no cabe duda que actúa más intensamente que las vibraciones más vigorosas. En síntesis, se participa de un concepto de la sexualidad a la manera Sade, y que consiste en llevar a su paroxismo el efecto cólera como si fuera el efecto gozo.

En la propuesta de Delacroix con su Muerte de Sardanápalo se había lanzado además un desafío tomando como referencia el mundo literario; es decir, por una parte los conocimientos con los que se había familiarizado durante su estancia en Londres 


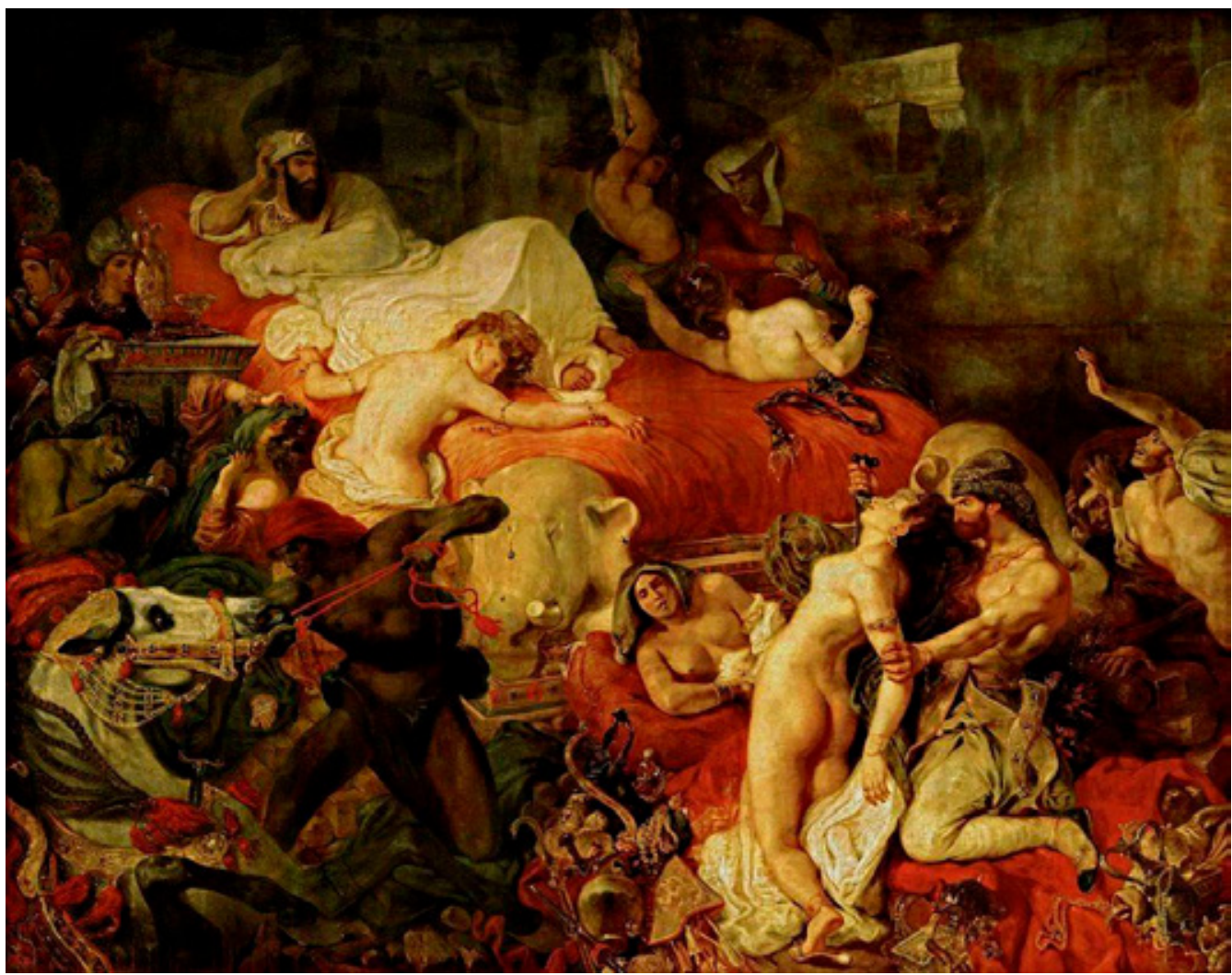

Fig. 4. La muerte de Sardanápalo, de Eugène Delacroix. 1827. Paris, Musée du Louvre

(desde Shakespeare al propio Lord Byron, Shelley, John Keats...), autores conocedores de una Grecia hundida en el abismo durante el enfrentamiento turco. Muerto a los 26 años, John Keats es el autor de la célebre Oda a una urna griega (1820). Se le considera el más joven de los grandes románticos ingleses, y al igual que ellos, su interés por la lucha de Grecia estaba centrado en la libertad. Con tal motivo Percey Shelley puso fin a su aventura literaria con el drama Helas (1822). Lord Byron será el encargado de rescatar su cadáver del agua e incinerarlo en el cementerio protestante de Roma, cerca de la tumba de John Keats. Pero el hombre que quiso hacer de su vida una obra de arte, Lord Byron, alcanzando gran popularidad como poeta, dramaturgo...; prototipo del héroe romántico, se desplaza a Missolonghi para contemplar de cerca el retrato que la crueldad impone a la libertad.

De igual modo hay que poner de relieve los rasgos esenciales de un capítulo que contribuye a descubrir aspectos de su vida y el alcance de lo que fue aquella pérdida de la libertad a recuperar y sobre la que nos hablaba Víctor Hugo tras su triunfo en Hernani. Es decir, el citado Arsenal literario de Charles Nodier, o espacio de acogida de la generación romántica que entrará en crisis tras la noche del 25 de febrero del año 1830 con el enfrentamiento inhabitual románticos y clásicos. Cuestión que potenciaba provisionalmente, la libertad de prensa, política... Se estaba anunciando los tres golpes de la libertad en las barricadas en los días 27, 28, 29 de julio de $1830^{10}$.

Sin embargo hay una cuestión que la derecha ultra desea lograr y finalmente alcanza: el restablecimiento del derecho de primogenitura, el agravamiento de la no libertad de prensa, la disolución de la Cámara, la modificación del régimen electoral, ordenanzas que produjeron de las primeras reacciones que condujeron a las Tres Gloriosas. Por lo mismo, los días de la revolución 
o triple y Gloriosa de julio de 1830, contribuiría a la aparición de un partido orleanista y con la defensa de una monarquía a la inglesa. Ahora bien tampoco se puede olvidar que, en realidad, el enfrentamiento entre la monarquía y Víctor Hugo (citado por Carlos $X$ como testigo para su coronación en Reims) estaba comenzando a derivar entre los románticos hacia una verdadera inquietud, especialmente desde julio del 1829. Fue un momento en que el poeta leyó ante Balzac, Delacroix, A. Dumas..., una obra que deseaba representar, su título era Marion Delorme. Sin embargo, el 1 de octubre esta obra quedó censurada; "prohibición que cayó como una macheta", aunque Víctor Hugo protestó en vano ante el ministro. Este fue el prólogo. Luego, puesto que para el rey no hay sistema de vigilancia, Carlos $X$ cuando entra en contacto con el escritor el 7 de agosto, será el nuevo ministro de interior quien le confirma la prohibición.

En otras palabras, existió un componente que ratificó hasta qué punto existían las mentiras o patrañas. Es decir, Víctor Hugo ante la censura tuvo un portavoz: el periodismo, en este caso Le Globe, liberal de izquierda; prensa muy premonitoria puesto que después de la revolución del 1830 empezó a quedar integrada por muchos redactores republicanos. Bien, pues este diario demostró no estar sometido, puesto que no se adaptó a lo que actualmente podría ser: "tener la sensación de estar controlado por ese Gran Hermano"; nos estamos refiriendo al editorial del 5 de agosto donde se pronosticaba el futuro apocalíptico o revolución de julio: "se ha cometido el primer golpe de estado literario". El ministerio pone obstáculos por todas partes; ataca sin titubear, tanto la literatura como el arte. Se podría decir que M. V. Hugo ha tenido el honor de recibir el primer golpe político en esta guerra a muerte que recomienza contra las ideas ${ }^{11}$.

Si se desea eludir un planteamiento de bazar, es necesario colocar las piezas que interesan sobre la biografía de Delacroix a partir de un discurso reflexivo en donde aparezca un capítulo que resulta básico, y al que se hizo breve referencia en un párrafo anterior: la organización del Arsenal Romántico, asimismo denominado el Salón de Charles Nodier (1824-1834). Si el Romanticismo representó en su momento una verdadera llamada de trompeta a la conciencia nacional a partir de 1815 con la restauración de la monarquía borbónica, y en especial con Carlos X, la medida de su grandeza en París viene determinada por el Arsenal Romántico de Charles Nodier. Un personaje que acogía cada domingo a la élite literaria y artística en los años de la Restauración y al comienzo de la Monarquía de Julio. Lejos de ser un lugar de diversión, el Arsenal implicaba una institución poliédrica en tanto que abierta a todas las especialidades: literaria, histórica, crítica, así como la pintura, la música, el teatro..., pero sobre todo constituía una biblioteca cuyo conservador en jefe fuera nombrado por el conde de Artois cuando todavía no había alcanzado la condición de Carlos $X$; es decir, el año anterior a ser coronado rey de Francia en sustitución de su hermano Luis XVIII. Su coronación en Reims contaría con la asistencia del propio Nodier, pero también de quien con el tiempo llegaría a ser uno de sus enemigos irreconciliables: Víctor Hugo. Ambos serían -Nodier y V. Hugo- los que alcancen la dimensión de patrones del movimiento romántico.

En cuanto al carácter de las reuniones en este cenáculo hay que tener presente que estaba integrado por un componente poliédrico. Así, entre otros, por A. Dumas (padre), Honoré de Balzac, Théophile Gautier -ferviente admirador de Víctor Hugo y de Delacroix-, Franz Liszt...; pero también Géricault, Delacroix, Chopin. Como se observará, todo un carrefour de personajes que constituyen el enclave de las nuevas ideas del momento; así, es necesario tener presente que muy pronto se dieron a conocer en este Arsenal obras cumbres, desde los Desastres de la guerra de Goya o el alborear de un nuevo mundo conforme a las teorías de Sade, quien representa la reivindicación de una libertad sin ley y sin miedo así como el cumplimiento extremo de la crueldad y del masoquismo, pero a pesar de todo es capaz de aceptar a la sociedad, sin crítica, puesto que nada posee de espíritu revolucionario. Autor-indiquémoslo una vez más- al que Simon de Beauvoir supo analizar con complacencia que era un cobarde al que un niño atrevido podría aterrorizar ${ }^{12}$.

Hay una cuestión en la que conviene hacer hincapié por lo que tiene de triunfo de la escuela romántica sobre los clásicos y premonición de fu- 
turo: el triunfo de Víctor Hugo con su obra Hernani. Momento en el que sus compañeros del círculo de Nodier lanzaron por primera vez el célebre grito el 25 de febrero de 1830 que anunciaba el que derrocaría a los Borbones en las barricadas de la Revolución de Julio de dicho año ${ }^{13}$.

Este llamamiento a la libertad constituye un referente de la batalla de los románticos. En especial para V. Hugo, desde Marion de Lorme y Hernani. Esta última constituía el prefacio en altavoz de lo que el autor entendía como consustancial con la soberanía del pueblo: la tolerancia y la libertad. Es más, la reconciliación. Es verdad que se distinguió muy pronto de los conservadores, pero cierto fue que desde 1830 su creencia en la república era un concepto que no le resultaba ajeno o, por lo menos, común entre los componentes del pueblo. Lo que le lleva a decir, siguiendo a Michel Winock, "yo no comprendo por qué se tiene miedo del pueblo soberano, puesto que el pueblo somos todos, lo que supone tener miedo de uno mismo". Tales fueron sus palabras en la plaza de los Vosgos cuando se presentó a las elecciones de la Asamblea Constituyente.

Pero sin duda donde V. Hugo planteó el verdadero prefacio de la llamada Guerra de las Tres Gloriosas (27, 28, 29 de julio de 1830) fue cuando tras el triunfo de Hernani reivindicó la libertad en el arte o, lo que es lo mismo, reivindicar la libertad de prensa, la libertad de expresión, las libertades políticas. En otras palabras: principio de libertad que, como escribía V. Hugo, es quien viene a renovar no solamente la actividad humana, sino también la sociedad. El poeta, con estas palabras, declaraba hasta qué punto estaba actuando como un profeta, puesto que será Delacroix quien dé forma a estas palabras con su famosa Libertad guiando al pueblo.

Aunque se impone la brevedad, resulta lícito considerar que en la obra de Delacroix los primeros años, a partir de 1823, resultan determinantes, ya que no fueron buenos tiempos para la política. En efecto, a medida que en Grecia cobraba entidad su lucha por la independencia ante el dominio del imperio turco, la Francia borbónica de Carlos $\mathrm{X}$ defendía una monarquía que se proponía derogar las leyes impías de la Revolución, sin dejar de imponer la pena de muerte. Es más: se podía decir que los Borbones de este

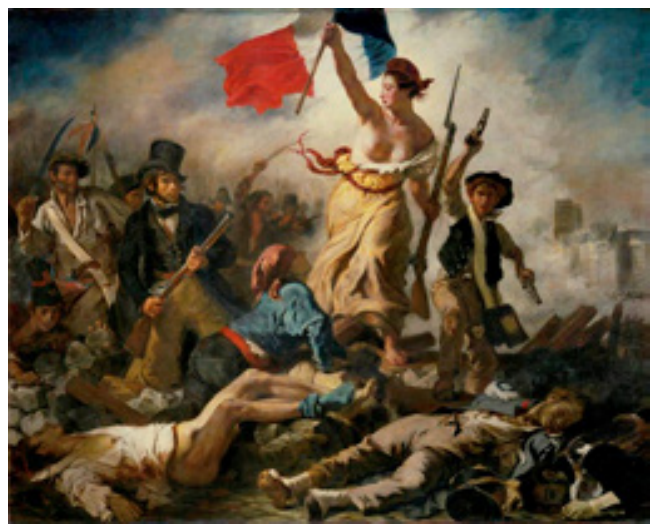

Fig. 5. La Libertad guiando al pueblo, de Eugène Delacroix. 1831. Paris, Musée du Louvre

momento consideraban que el mal había llegado a su máxima potencia. Este pensamiento, afín a la derecha ultra, fue el primero en ganarse el exilio después de la revolución de julio de 1830, inmortalizada por Delacroix en su célebre óleo sobre la Libertad en las barricadas (fig. 5).

Mientras, el Romanticismo se estaba convirtiendo en un movimiento de protesta, en especial contra ese mundo que tiene su origen en Joseph de Maistre (1753-1821), contemporáneo de la Revolución, para quien el sistema político emanaba de la voluntad divina. Por consiguiente, existen varios datos a considerar. Primero: el hombre no es libre, y solo una inteligencia superior (la Divina Providencia) puede someterse. De aquí, segundo: que Dios determine las "razas reales"; además, se había llegado de nuevo a un momento de triunfo o alianza trono-altar, a cuyas decisiones las naciones y la comunidad habrán de someterse. Por otra parte, se consideraba que nadie podía ser digno de honores públicos, de reconocimiento por su grandeza política, cultural...

Gérard Gengembre, profesor de literatura de la Universidad de Caen, estudioso y analista de las ideas políticas contra-revolucionarias, recuerda como entre los nostálgicos de J. de Maistre todavía figuran nombres vigentes a día de hoy ${ }^{14}$. Ello impone considerar que era también el momento del antes nombrado vizconde Louis de Bonald; si se recuerda, estaba encargado de la comisión de censura en la monarquía de Carlos $X$ desde 1827 . Si se sigue con sus comparaciones, tenía una asombrosa capacidad para utilizar 
argumentos para el "todo vale", así los que atañen a su asociación con la Revelación Divina. Por ejemplo, considera la Revolución de 1789 como el mal elevado a su máxima expresión, y puesto que el poder procede de Dios, el hombre carece de derechos, al tiempo que hace tabula rasa del individualismo. En la perspectiva de este ultra defensor de la monarquía tradicional, autor de la "teoría del poder político y religioso", parecía que la condición humana solo tenía responsabilidades, obligaciones, pero no derechos ${ }^{15}$.

Declaraba Michel Winock, profesor del Instituto de Estudios Políticos de París, en su análisis sobre "la derecha nacida con la Revolución Francesa", que su anti-individualismo era una manera de demostrar "la necedad filosófica y antropológica del individualismo", puesto que solo hay personas, mortales, seres diferentes, determinados por su origen y su medio. De manera que únicamente dentro de este prosaico principio intuye que el pueblo solo tiene que aceptar las leyes elegidas por el que fue delegado con una misión católica para reconvertir al pueblo.

En este contexto de violencia extrema, absolutismo, restablecimiento de los valores del Antiguo Régimen, prerrogativas de la nobleza y la Iglesia, ministros ultramonárquicos que provocan el descontento..., la pregunta es: ¿puede sorprender que las mentes líderes, aquellos grandes maestros, se reúnan los domingos en el Arsenal Romántico de Charles Nodier? En otras palabras, ¿acaso no supuso una expresión de rebeldía este unir cada una de ellos su yo cósmico con un deseo de salvar a su país a partir del rasgo más destacado del mundo romántico como es la procura de la libertad individual? La respuesta llegará de la mano de Víctor Hugo y de Delacroix cuando al rematar el julio de 1830 el gobierno de los Borbones, las dos obras que marcarían un hito fueron Víctor Hugo con Notre Dame de Paris (1831) y Delacroix con La Libertad guiando al pueblo (1831). Obra esta última donde aparece al fondo del escenario la propia catedral del Sena.

\section{El carácter mítico de la libertad a partir de la III República}

En este momento adquiere un carácter icónico desde que el Ministro de Instrucción Pública Jules Ferry contribuye a llevar adelante las expec- tativas reguladoras sobre la manera de educar una nación. Nacía así, en los años 1879-1883, la escuela republicana laica, encargada de formar conciencias y de instaurar reuniones, libertad de prensa, libertad sindical, libertad para las leyes de divorcio... se trataba en definitiva de una república doctrinaria que suscitaba la enseñanza de la Historia en plena valoración del centenario de la Revolución de 1789, la Marsellesa como himno nacional, y lo que conlleva el nacimiento de toda una imaginería republicana. En otras palabras, se estaban recobrando los derechos y deberes del hombre y del ciudadano, las libertades y los ideales, pero no los derechos y deberes de la mujer, como había sido la propuesta de la I República. En definitiva el atractivo por esta obra propone -tal es mi criterio- que el pensamiento político de Delacroix correspondía a un consenso con los principios del régimen republicano, que desembocaría en la II República (1848-1852). Resulta curioso que a la vez que la defensa de la república se establece, las representaciones de la Libertad, Marianne, se multipliquen.

Un famoso ejemplo de lo que fue la imagen en acción lo representa, como se viene indicando, el tema de La Libertad guiando al pueblo (fig. 5). Un óleo sobre lienzo de $260 \times 325 \mathrm{~cm}$ donde se establece una confraternidad entre el hombre con levita y el que dispone de blusa o chambra; es decir, entre el dandy y el liberal o burgués, que son los símbolos de la gran popularidad que alcanzan el 27, 28 y 29 de julio de 1830 las masas populares y liberales francesas cuando se lanzan a la calle en respuesta a las medidas y ordenanzas fuertemente conservadoras adoptadas por el monarca Carlos X, quien se vio incapaz de controlar dicho movimiento revolucionario, para ser derrocado a favor de Luis Felipe de Orleáns. Esta obra, realizada por Delacroix en muy poco tiempo, llegaría a convertirse en el icono mundial de la libertad y la revolución.

De un cuadro que conmemora el descontento de un pueblo, en especial la burguesía, ante las reformas políticas llevadas a cabo por el monarca y por su ministro Polignac, de manera que representaba esta obra el triunfo sobre las enérgicas Ordenanzas promulgadas el 26 de julio de 1830. Estas medidas supusieron un rechazo a la libertad de expresión, la vuelta al derecho de primogeni- 
tura, y sobre todo la crisis de normas ya reguladas en el seno de aquel grupo social. Se trataba de hacer frente, por consiguiente, a una monarquía absolutista, y tomar como nueva propuesta un gobierno republicano. Pero será el comandante de la guardia municipal, Lafayette (a quien se le llega a proponer la presidencia de dicha república, a la que renuncia) quien proponga como solución guiada una monarquía constitucional con Louis-Philippe d'Orleans; posición alentada por el banquero Laffitte, el historiador y ministro Thiers, amigo de Delacroix, y de Rude.

Si bien Carlos $X$ sería depuesto el 31 de julio de 1830, las propuestas enviadas al duque de Orleáns por aquel monarca para que abdicara a favor de su nieto fueron mensajes sin resolución. Por añadidura, aquella derecha ultra o borbóni$\mathrm{ca}$, se ve obligada entonces al destierro o a ser partícipe del nuevo aspecto en la vida política: la nueva imagen de la derecha liberal es que ansía ser partícipe de un sueño que hasta ahora era fuego de artificio. Es decir, se trata de activar un régimen de compromiso entre monarquía y revolución. Ahora bien: aunque los republicanos habían llevado el peso de la revolución, carecían de líderes para llevar a término tal proceso. Al mismo tiempo tal situación política no contaba con la aprobación de la Triple Alianza (Rusia, Austria y Prusia), como tampoco de Inglaterra. Ahora bien, en Bélgica también se hace frente al absolutismo, como en Polonia, lo que significaba que los gobiernos estaban dominados por ministros ultramonárquicos, un limitado poder de las cámaras y un descontento creciente entre la burguesía liberal, con crisis económica, así como hambrunas entre las clases populares.

Nada hay de significativo entonces que los románticos, desde Víctor Hugo a Delacroix, antaño defensores del Antiguo Régimen, sean los primeros en adoptar una actitud de intenso subjetivismo ante las cuatro Ordenanzas de Saint-Cloud, promulgadas el 25 de julio de 1830, donde se abolía, como ya quedó indicado, desde la libertad de prensa hasta la entrada de la oposición en la Cámara. Víctor Hugo y Delacroix también se decantan por la defensa de la libertad de los pueblos y las víctimas sociales. Y así, en 1831, al primero corresponde la publicación de Notre Dame de Paris, y al segundo La Libertad en las barricadas. Una obra presentada en el salón de 1831, que toma como principal referente el descontento del pueblo -y en especial de la burguesía- ante las reformas políticas llevadas a cabo por el rey Carlos $X$.

La obra fue adquirida por el Estado francés y expuesta en el Salón en ese mismo año 1831, recibiendo duras críticas, según parece, por la representación de una mujer semidesnuda, entre otros factores, no volviendo a ser expuesta definitivamente hasta la Tercera República, coincidiendo con la enseñanza de la Historia y los manuales de historia en la enseñanza primaria y secundaria francesa, así como en un momento de gran interés por abordar los problemas de fronteras en relación con el nacimiento de la nación francesa, la dominación romana y, sobre todo, enfocar y valorar la revolución francesa de 1789, 1830, y la de 1848; un momento en que el director del Museo del Louvre reclamó la presencia de este cuadro durante breves períodos, hasta que en 1863 , tras la muerte de Delacroix, quedó expuesto definitivamente en una de las salas del museo.

A modo de preámbulo, siempre se ha considerado que Delacroix se mantuvo al lado de los revolucionarios, representando como imagen central de su obra una mujer de pecho descubierto, y portando bandera tricolor al igual que un fusil con bayoneta. ¿Obra de encargo? Tal vez, puesto que surge cuando comienza a ocupar el potro del poder como ministro de Interior, en tiempos de Luis Felipe de Orleáns, Louis A. Thiers (quien llegaría incluso a ser presidente de la Tercera República).

Aunque habrá que volver sobre este óleo en párrafos sucesivos, aquí interesa manifestar que se trataba de representar la alegoría de la República francesa guiando hacia la victoria a un grupo de revolucionarios burgueses. Delacroix estaba muy habituado a desarrollar lienzos que evidenciaban un manifiesto interés por "las riendas de la política, el látigo de la justicia, la espuela del valor..., incluso los estribos de la prudencia" ${ }^{16}$. En este sentido sus óleos sobre la independencia griega ante el imperio otomano no buscaban concretizar la acción militar; sí, por lo contrario, los efectos negativos de una larga guerra en curso. Y esto, cuando los museos de París y Londres eran el nuevo lugar de residencia del Partenón y la Venus de Milo. 


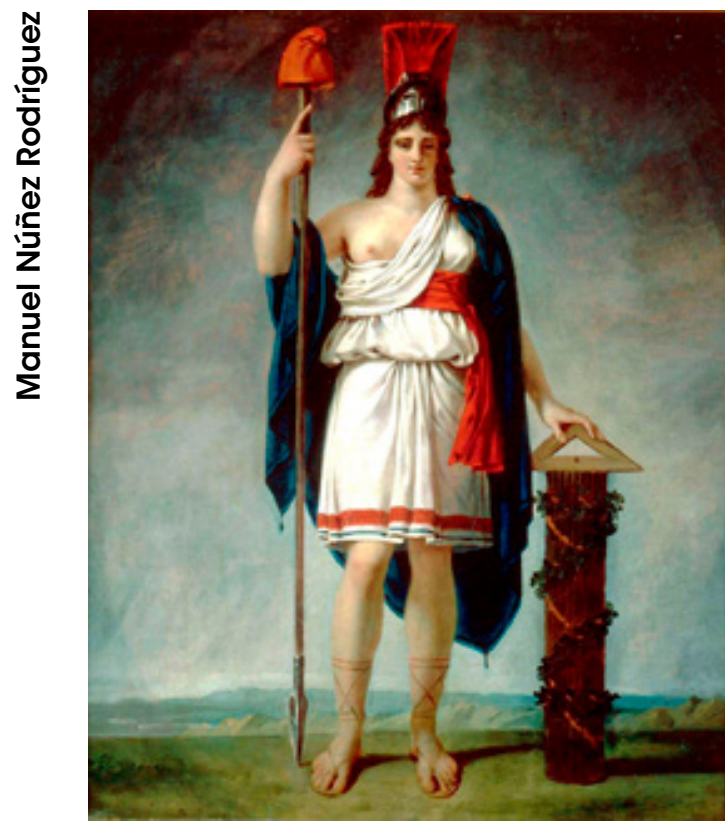

Fig. 6. Figura alegórica de la República atribuida a Jean Antoine Gros. Fines del siglo XVIII (Versailles, Colección Giraudon)

Otro concepto importante que queda plenamente patente es la manera de plantear aquella noche del 27-28 de julio de 1830, donde, en función de los relatos y grabados periodísticos sobre la barricada levantada en el puente que une la îlle de la Citè con la orilla derecha de París, vuelven a cobrar valor los ideales de la Revolución de 1789, a los que el ahora denominado Rey de los Franceses (y no Rey de Francia, como también "reyciudadano Luis Felipe") rindió homenaje a partir de la bandera tricolor. De esta forma, mientras se iba forjando el mito del Rey-burgués, en paralelo los republicanos se reorganizaban en sociedades, constituyendo otra propuesta importante desde la reorganización de sociedades de los Derechos del Hombre y del Ciudadano, que desde 1833 aventajaba a las demás hasta la emancipación de la clase obrera.

En tal sentido, en este lienzo el que había sido gran admirador de Goya y conocedor de su obra El 3 de mayo de 1808 (Museo de Prado, 1814), aprovechando el pleno empleo de la litografía, tan útil para la caricatura como la prensa y la pintura romántica, sin duda tuvo que estar familiarizado con muestras presentes en los escaparates de las tiendas, en especial las vinculadas a planteamientos sobre la muerte heroica. La pregunta que corresponde hacer entonces es: ¿ pudo haberse inspirado en litografías de época, dado su bajo precio, puesto que, además, estaban elaboradas en color? Se descubren en 1789 y obtienen gran éxito a lo largo del siglo XIX, siendo una de las más reproducidas la que representaba el asalto a la Bastilla. La idea parece cobrar fuerza en esta representación, correspondiente al 28 de julio de 1830, donde el contenido del mensaje icónico de la libertad y el pueblo invocan la visión política que glorifica al pueblo de Francia, y que Delacroix reproduce a partir de una figura alegórica de la Primera República (fig. 6) atribuida a Jean Antoine Gros: imagen que representaba en origen a la República vestida a la antigua, con un pecho al descubierto, bonete frigio sobre la lanza, y que formaba parte del programa de instrucción cívica y moral desde la enseñanza primaria. Como dice Mona Ozouf, pasaría a convertirse este emblema de la república en antimonárquico y, por consiguiente, en antirrevolucionario. Aunque faltan muchos datos para recomponer el rompecabezas en que derivó la imagen de la Libertad, es necesario tener presente que en la Primera República, entre las divinidades que representaban un culto especial, figuraba la diosa Feronia, de la que existen medallas de tiempos de Augusto representándola con una corona y asociada a los libertos, dado que cuando eran puestos en libertad en su templo se les colocaba el sombrero o bonete afín al que muestra esta guerrera de Jean Antoine Gros vestida con una lanza y un bonete frigio (fig. 6). Entonces, ¿merecía en verdad una diosa tan célebre como Feronia el homenaje de quienes alcanzaban la libertad desde tiempos de la República?

Para concluir, ¿no parece arriesgado abordar la célebre obra La Libertad guiando al pueblo bajo el título El escándalo romántico de Delacroix en 5 telas? Pues esta es la convicción que inspira el trabajo de Pierre Rupert al abordar La barca de Dante (1822), La muerte de Sardanápalo (1827)... Con Delacroix no se puede decir que llegara el escándalo, formaba parte del innovador Arsenal de Charles Nodier. Su labor nada tenía que ver con la regla académica, pero sobre todo su acto creativo hay que valorarlo con el alcance de los tres colores primarios: rojo, azul y amarillo; el rojo es complementario del verde (obtenido del azul y 
amarillo), el amarillo pasa a ser complementario del morado (mezcla del rojo y azul), y el azul es complementario del anaranjado (mezcla de rojo y amarillo). Tampoco era concordante con la realidad, puesto que buscaba la imaginación creadora; algo que le llevaba a preguntarse: ¿qué significa una burguesa gorda vista de espaldas y desnuda? (tal fue su juicio sobre la obra de Courbet). Sin embargo, amaba los tipos populares de Murillo.

Pero no se podría concluir sin considerar cuál era su reflexión sobre la realidad de lo que denominaba "el arte de la guerra": "siempre se habla de la libertad, es el fin de todas las revoluciones, pero no se dice lo que esa libertad. En el estado más libre, ¿quién es completamente libre?". Se diría que estas palabras todavía invocan los desgraciados recuerdos de Janis Joplin respecto a las verdaderas pasiones o sentimientos de quienes aspiran a inmolarse por su patria. Sin embargo, Delacroix, aun cuando admiraba a Napoleón, los cuadros referidos a sus combates no representaban para él un desafío, puesto que era partidario de la abolición de las armas defensivas que deberían ennoblecer la profesión del soldado. 
NOTAS

1 Existen múltiples trabajos sobre Baudelaire en defensa de la originalidad creadora, la evolución técnica, así como la habilidad y rapidez de E. Delacroix. Sin embargo, debo decir que para el historiador del arte resulta mucho más preciso el análisis del profesional de la literatura cuando se trata de redescubrir las circunstancias que rodean a un personaje como Delacroix, puesto que su estética es la expresión de las mágicas virtudes del color, de la música, pero también de la literatura, en concreto de la poesía.

${ }^{2}$ Charles Baudelaire, Las Flores del Mal, ed. Bilingüe de Alain Verjat y Luis Martínez de Merlo, Cátedra, Madrid, 2013, p. 263

3 Michel Winock, "Les quatre familles de la droite: acte II, Les trois droites, 1815-1880", Les Collections de L'Histoire, trimestriel, $n^{\circ} 14,2002, p p$. 12-14
4 Simone de Bouvoir, Faut-il brûler Sade?, traducción J. E. de la Sota: El Marqués de Sade, Ediciones Leviatán, Buenos Aires, 1956; así como Edw. Lucie-Smith o G. Bataille, entre otros no dudan en definir como "la Revolución francesa"

${ }^{5}$ Linda Nochlin, "Les femmes, I'art et le pouvoir", Les Cahiers du Musée National d'Art Moderne, $n^{\circ} 24$, été 1988, pp. 45-61.

${ }^{6}$ Edward Lucie-Smith, La Sexualitè dans l'Art occidental, Cicero, París, 1995, pp. 107-110.

7 Pierre Francastel, Historia de la pintura francesa, Alianza editorial, Madrid, 1978, p. 492

8 Simone de Beauvoir, El Marqués... op. cit., p. 4.

${ }^{9}$ Charles Baudelaire, Delacroix, vida y obra, Casimiro Libros, Madrid, 2011, p. 46
${ }^{10}$ Michel Winock, "Scènes de guerre à Paris: la batalla d'Hernani", L'Histoire, n² 240 fevrier 2000, p. 19-21.

${ }^{11}$ Ibidem, p. 20.

${ }^{12}$ Simone de Beauvoir, El Marqués... op. cit., p. 7.

${ }^{13}$ Michel Winock, "1802-1885. La traversée du siècle", L'Histoire, $n^{\circ} 261$, janvier 2002, pp. 34-45.

${ }^{14}$ Gérard Gengembre, "Les nostalgiques de l'Ancien Régimet", L'Histoire, $n^{\circ}$ 219, mars 1998, pp. 38-63, espec. pp. 44-45. Su influencia ha sido intensa entre intelectuales de extrema derecha, y así en la actualidad al diario lepenista Présent. En 1956 formaba parte del movimiento extremista de Pierre Poujade, quien se abre paso en las elecciones presidenciales de enero con 56 diputados.

${ }^{15}$ Gérard Gengembre, "Les nostalgiques... op. cit., p. 45.

${ }^{16}$ Peter Burke, El uso de la imagen como documento histórico, Crítica, Barcelona, 2005, pp. 76-77. 


\section{REFERENCIAS}

Baudelaire, Charles. 2011. Delacroix, vida y obra. Madrid: Casimiro Libros.

Baudelaire, Charles. 2013. Las Flores del Mal. Edición bilingüe de Alain Verjat y Luis Martínez de Merlo. Madrid: Cátedra.

Beauvoir, Simon de. 1956. El Marqués de Sade. Faut-il brûler Sade?. Traducción de J. E. de la Sota. Buenos Aires: Ediciones Leviatán.

Burke, Peter. 2005. El uso de la imagen como documento histórico. Barcelona: Crítica.

Delacroix, Eugéne. 1998. El puente de la visión. Antología de los diarios. Madrid: Ed. Tecnos.

Francastel, Pierre. 1978. Historia de la pintura francesa. Madrid: Alianza Editorial.

Gengembre, Gérard. 1998. "Les nostalgiques de l'Ancien Régime." L'Histoire 219, (Mars): 38-63.
Lucie-Smith, Edward. 1995. La Sexualitè dans l'Art occidental. Paris: Cicero.

Néret, Gilles. 2002. Eugéne Delacroix. Colonia: Taschen.

Nochlin, Linda. 1998. "Les femmes, I'art et le pouvoir." Les Cahiers du Musée National d'Art Moderne 24 (Été): 45-61.

Rosst, Luigina. 1973. La obra pictórica de Delacroix. Barcelona: Noguer.

Winock, Michel. 2000. "Scènes de guerre à Paris: la bataille d'Hernani." L'Histoire 240 (Fevrier): 19-21.

Winock, Michel. 2002. "1802-1885. La traversée du siècle." L'Histoire 261 (Janvier): 34-45.

Winock, Michel. 2002. "Les quatre familles de la droite: acte II, Les trois droites, 1815-1880." Les Collections de L'Histoire 14 no. trimestriel: pp. 12-14. 
